\title{
SINDROME 'ONE-AND-A-HALF'
}

\author{
CONSIDERAC̆óES ANATOMOCLINICAS A PROPÓSITO DE UM CASO
}

\author{
CHARLES ANDRE * - ANA LOCIA Z. DE CASTRO* - MAURICE B. VINCENT * \\ JAMES PITAGORAS DE MATTOS** - PERICLES DE A. MARANHAO FILHO* \\ SERGIO A. PEREIRA NOVIS ***
}

\begin{abstract}
RESUMO - Um homem pardo de 36 anos foi internado em setembro de 1987, referindo que há 5 anos sofria episódios recorrentes de cefalẹia, zumbidos, náuseas, diplopia e estrabismo divergente recentemente associados a paresia facial. Os episódios, num total de 4, invariavelmente regređiam sem sequelas ao longo de poucas semanas. $\grave{A}$ internação, o paciente apresentava exotropia do olho direito à mirada natural, paralisia do olhar conjugado para a esquerda, paralisia da adução do olho esquerdo, abdução do olho direito preservada com surgimento de nistagmo ritmico horizontal. Os movimentos oculares verticais e de convergência estavam preservados. Havia ainda paralisia facial periférica à esquerda e sinal de Babinski à direita. O exame dos potenciais evocados revelou apenas laténcia aumentadia dos potenciais auditivos pontomesencefálicos. A tomografia computadorizada revelou lesāo hipodensa nāo captante de contraste no tegmento pontino e atrofia da busis pontis à esquerda. O exame do LCR revelou hiperproteinorraquia e aumento da IgG. Os exames dopplerométrico, parangiográfico e ecocardiográfico bidimensional foram normais. O diagnóstico final foi de sindrome 'one-and-a-half' (SOAH) por possivel lesão desmielinizante pontina esquerda, sendo iniciado tratamento imunossupressor. A SOAH é de reconhecimento clínico fácilı, porém fundamental, por sua morbidade e pelas possibilidades diagnósticas e terapêticas que sugere.
\end{abstract}

\section{'One-and-a-hajf' syndrome: anatomic and elinical considerations based on a case.}

SUMMARY - A 36 years-old man was admitted in September 1987. For 5 years he suffered from 4 recurrent episodes of throbbing headache. tinnitus, nausea, diplopia and divergent strabismus to which a facial palsy was recently added. In all episodes, the symptoms disappeared spontaneously and completely. A neuro-ophthalmological examination at admission disclosed an exotropia of the right eye, gaze paralysis to the left, paralysis of adduction of the left eye and preserved right eye abduction which triggered a rhythmic horizontal nystagmus. The upward and downward gazes and the convergence were well preserved. Moreover, there was a left peripheral facial palsy, and Babinski sign at the right side. Auditory evoked potenciais were slowed at the mesencephalopontine transition. CT scan showed a low-density area with no contrast enhancement at the left pontine tegmentum and a left anterolateral atrophy of the pons. CSF exmination showed increase in protein content and increase in the IgG content. Additional investigation included a dopplerometry of the cervical arteries, a panangiography and a bidimensional echocardiography which were normal. Diagnosis of one-and-a-half syndrome was made. possibly secondary to multiple sclerosis, and immunossupressive therapy was initiated.

Trabalho realizado no Serviço de Neurologia do Hospital Universitário Clementino Fraga Filho (HUCFF), Universidade Federal do Rio de Janeiro (UFRJ) (Chefe do Serviço: Prof. Sérgio Novis): * Neurologista; ** Chefe de Clínica; *** Chefe de Serviço. 
O presente trabalho justifica-se pela observação recente de um caso de síndrome 'one-and-a-half' (SOAH), caracterizada por paralisia do olhar conjugado para o lado da lesão e paralisia da adução à mirada contralateral, com abdução preservada e nistagmo do olho contralateral à lesão. A convergência ocular estava preservada. A SOAH é rara, havendo menos de 50 casos descritos na literatura mundial. Sua semiótica é característica e permite reconhecimento clínico seguro. O diagnóstico sindrômico precoce tem grande importância prática, já que a SOAH comporta etiologias variadas e potencialmente graves, que exigem investigações e têm implicações terapêuticas muito especificas. Consideramos, portanto, justificável uma revisão sumária das vias neurais envolvidas e dos achados clínicos nesta condição.

Fisiologia do olhar conjugado horizontal - Os movimentos oculares conjugados (MOC) podem ser divididos em dois grandes grupos: A. Relacionados ao movimento do individuo. Os MOC vestibulares e optocinéticos são responsáveis pela manutenção de uma imagem estacionária na retina durante o movimento de rotaçâo da cabeça. $O$ reflexo vestíbulo-ocular produz desvio ocular lento, contralateral ao aparelho vestibular estimulado no início do movimento cefálico. Este movimento, se uniformemente mantido, gera respostas optocinéticas que se sobrepōem aos impulsos vestibulares. B. Relacionados à posição e à movimentação dos alvos: São os MOC sacádico, de perseguição e de vergência. Os movimentos sacádicos são desvios rápidos dos olhos, visando trazer para a fóvea, área de maior acuidade visual, objeto que esteja colocado na periferia do campo visual. Movimentos de perseguição permitem que um alvo em movimento possa ser mantido sobre a mácula. A vergência do olhar centraliza objetos pela movimentação oposta dos globos oculares, proporcionando a noção de profundidade da visão e evitando a diplopia.

Independentemente do MOC realizado, a via efetora é comum, variando apenas suas aferências. O centro do olhar conjugado horizontal está localizado na ponte e envolve o núcleo do nervo abducente $\mathrm{e}$ a formação reticular pontina paramediana (FRPP) a ele adjacente (Fig. 1A e B). Esta formação ocupa uma região sem limites histológicos precisos, basicamente rostral ao núcleo do abducente, estendendo-se no sentido rostral até o brachium conjunctivum e o núcleo do troclear 6 . Dois são os tipos celulares presentes nesta formaçăo, quais sejam os neurônios magnocelulares, que inervam o músculo reto lateral do mesmo lado; os neurônios internucleares, cujos axônios cruzam para o lado oposto e ascendem até o subnúcleo do reto medial do nervo oculomotor comum (porçăo inferior), via fascículo longitudinal medial (FLM). Isto permite diferenciar, num paciente com dificuldade para abduzir o globo ocular, uma lesão nuclear de uma lesão periférica do nervo abducente pois, nesta, a adução do globo

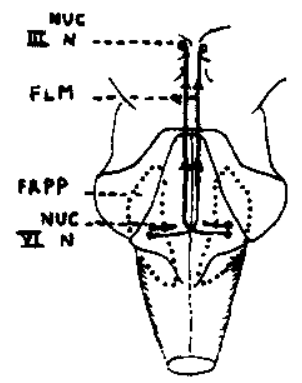

A

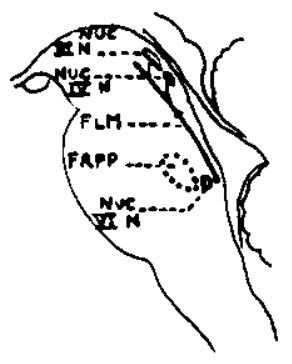

B
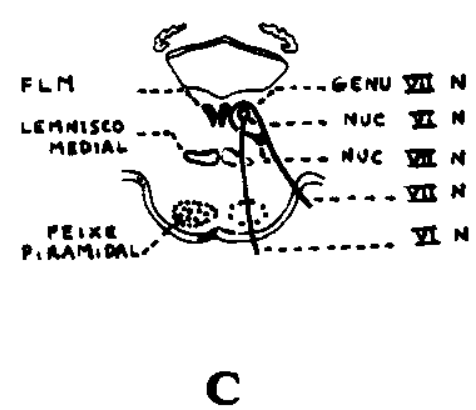

Fig. 1 - Aspectos anatómicos de interesse. $A$ $E$, representacão esquematica do tronco cerebral, visto por sua face posterior (A) $e$ em corte sagital (B). Conexäo dos núcleos do VI nervo (ponte) e III nervo contralateral (mesencéfalo) via fascículo longitudinal medial. C, Corte coronal a nivel da ponte. Notar o trajeto intrapontino do nervo facial, que circunda o núcleo do VI nervo, a proximialade deste genu facial com o fasciculo longitudinal medial, a relacão anatómica entre o lemnisco medial, carreador da sensibilidade tatil, o feixe piramidal (corticoespinhal) $e$ a região de interesse, posterior (tegmento pontino). Nuc III N, núcleo do nervo oculomotor comum; Nuc VI $N$, núcleo do nervo labducente; Nuc IV $N$, núcleo do nevvo troclear; GENU e Nuc VII N, joelho e núcleo do nervo facial; FLM, fasciculo longitudinal medial; FRPP, formação reticular pontino paramediana, ou centro do olhar conjugado horizontal. 
ocular contralateral está preservada. A divisāo funcional das subpopulaçōes neuronais da FRPP é bem mais complexa que a divisāo histológica. Segundo Zee e Leigh 9, a movimentação ocular sacádica horizontal se faz às custas de potente contraçẫo dos músculos oculares em resposta a neurônios disparadores (excitatory burst cells), localizados na FRPP. Após o deslocamento rápido inicial, os olhos devem ser mantidos em sua nova posição, vencendo forças elásticas que tendem a provocar seu retorno à posição neutra (fixação visual). Neurônios tônicos ('tonic cells'), de localização menos precisa, se encarregam desta etapa. Um terceiro grupo celular, chamado de neurônios de pausa ('pause cells'), localiza-se próximo à linha média, rostral ao núcleo do abducente. Estes neurônios apresentam descargas tônicas intercaladas por pausas, exceto imediatamente antes e durante os movimentos oculares sacádicos. Exercem, portanto, influência inibitória sobre os neurônios disparadores durante períodos de fixaçăo visual. Existem ainda outros grupos de neurônios inibitórios, de menor interesse clinico entretanto.

Algumas palavras sobre o controle supranuclear do olhar conjugado horizontal devem aqui ser inseridas. A área frontal do olhar conjugado horizontal, área 8 de Brodman, conecta-se, entre outras estruturas, com a FRPP contralateral. Sua estimulação por microeletrodo produz. MOC contralateral, enquanto sua lesāo produz desvio tônico dos olhos para o mesmo lado e incapacidade de impedir voluntariamente MOC sacádicos reflexos provocados por objetos apresentados ao campo visual contralateral. O lobo occipital, através do colículo superior, emite fibras que convergem para a FRPP ipsilateral. Descargas do colículo superior provocam desvio contralateral dos olhos, especialmente quando surge um novo estímulo no campo visual. O cerebelo e outras regiões como o lobo parietal também influenciam o surgimento de movimentos sacádicos. Lesōes em cada uma destas regióes são capazes de produzir alterações características da posição ocular ou dos movimentos sacádicos. A discussão mais extensa destas alteraçōes do controle supranuclear do olhar conjugado horizontal foge dus objetivos deste artigo, podendo ser encontrada em textos recentes 7,9 .

\section{OBSERVAÇÃO}

CVB, um homem pardo de 36 anos deu entrada no HUCFF-UFRJ em setembro de 1987 porque, ao acordar, notou presença de diplopia, estrabismo divergente, náuseas e vômitos, sem cefaléia, zumbidos ou quaisquer outras queixas. Sua históría clínica, entretanto, iniciava-se 5 anos antes, com a instalaçảo súbita de diplopia, vômitos, cefaléia bifrontal pulsátil de forte intensidade e acúfenos, mais acentuados à esquerda (E). Houve recuperaçăo espontânea e completa, permanecendo o paciente assintomático por dois anos. Nesta época, um quadro em tudo semelhante se desenvolveu, novamente com regressão espontânea, sem sequelas. Um ano antes de sua internação, novamente surgiram diplopia e cefaléia, desta vez associados a perda de força muscular na hemiface $E$. Novamente louve recuperação completa, até a recorrência clínica que motivou sua internaçāo. Sua história clínica pregressa era inexpressiva; o paciente, fumante há 21 anos (cerca de 20 cigarros ao dia), utilizava esporadicamente cocaína por via inalatoria. O exame geral era inexpressivo. Ao exame neurológico, constatou-se marcha com desequilibrio para a $\mathbf{E}$, nomalizada após o fechamento monocular; sinal de Babinski à direita (D); paresia facial periférica à $\mathbf{E}$ (Fig. 2F), com redução do reflexo corneo-palpebral, sem alteração da sensibilidade facial e com mastigação normal. o exame neuro_oftalmológico revelou diversas alteraços (Fig. $2 \mathrm{~A}$ a E); à mirada de repouso para a frente, notava-se exotropia do olho D; havia paralisia do olhar conjugado horizontal para a $E$ e paralisia da adução do olho $E$; a abdução do olho $D$, preservada, desencadeava nistagmo rítmico monocular horizontal; os movimentos oculares verticais e a convergência estavam normais, assim como a motilidade pupilar e o aspecto retiniano à fundoscopia. Os exames complementares de urina e sangue foram normais, exceto por leve opalescência do soro com hipercolesterolemia (colesterol total $260 \mathrm{mg} / \mathrm{d}$ ). A reaça ao PPD foi de $12 \mathrm{~mm}$. O exame de liquido cefialorraquidiano (LCR) revelou proteinorraquia discretamente elevada ( $48 \mathrm{mg} / \mathrm{dl})$, com o seguinte padrão eletroforético - albumina 61,5\%; globulinas: alfa-1 4,8\%, alfa-2 $6,3 \%$, beta e tau 13.2\%, gama $10,7 \%$ (normal até 13\%). Imunoeletroforese do LCR: IgG $4,3 \mathrm{mg} / \mathrm{dl}$ (normal até $3,6 \mathrm{mg} / \mathrm{d} 1$ ), IgG/proteina total 0,9 (normal até 2,2), IgG/pré-albumina + lalbumina 1,4 (normal até 3,4 ); os achados, em conjunto, não eram indicativos de imunoliberação. Uma primeira tomografia de crânio (TC) foi normal; repetida após 15 dias, com cortes finos e infusáo dupla de contraste iodado, revelou pequena área hipodensa em topografia da ponte, à E, associada a alguma redução volumétrica da face anterolateral $\mathbf{E}$ da ponte (Fig. 3). A panangiografía cerebral, foi inicialmente questionada a presença de um 'flush' radiopaco, ou seja, pequeno borramento de contornos vasculares dos ramos panamedianos da porçāo mais distal da artéria basilar; revisão criteriosa do exame, entretanto, permitiu concluir por normalidade do aspecto encontrado. O paciente submeteu-se ao estudo dos potenciais evociados de natureza tátil 
(sômato_sensitivo), visual e auditiva: os dois primeiros furam normais, enquanto 0 exame dos potenciais auditivos demonstrou curvas de I a III normais, mas aumento da latência entre os potenciais III e V, pontomesencefálicos, somente à E. Foram ainda realizados estudos eccardiográficos bidimensional e dopplerometria dos vasos do pescoç, ambos inteiramente normais. O paciente teve melhora espontânea nos primeiros 5 dias de internação, voltando a piorar na semana subsequente. Cerca de um mês após a internação recebeu alta assintomático. Dois meses após, em acompanhamento ambulatorial, voltou a apresentar diplopia e paresia facial $\mathrm{E}$, sendo decidida a introdução de terapia imunossupressora, inicialmente com prednisona,

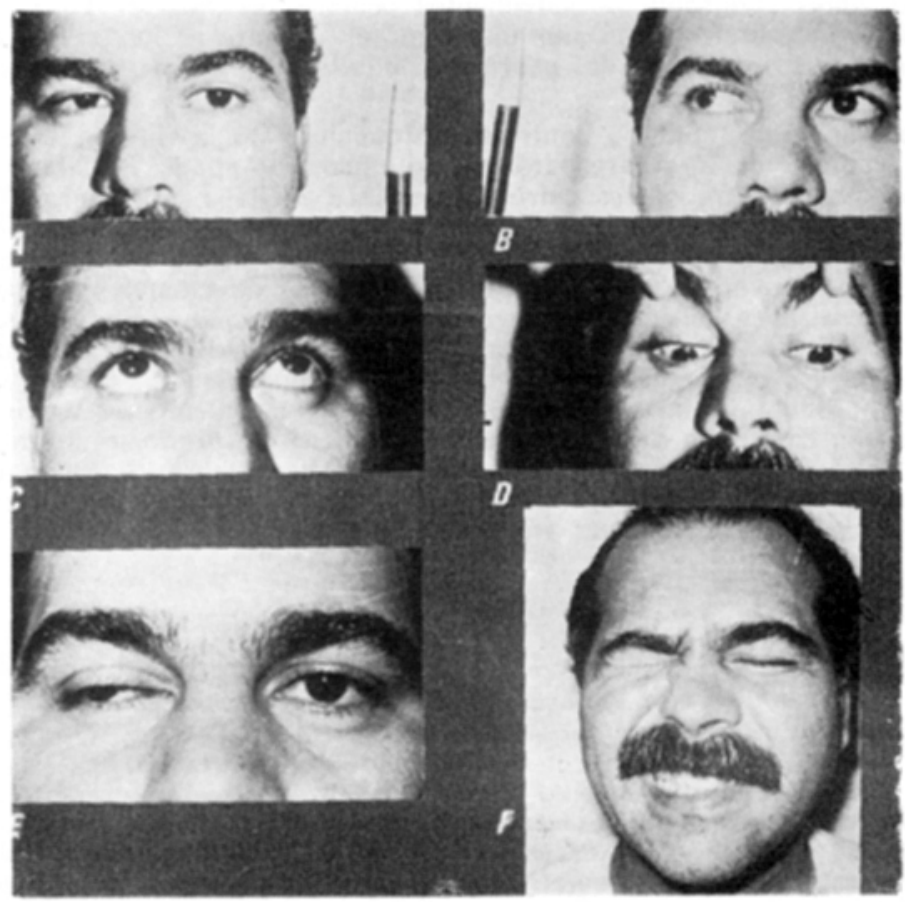

Fig. 2 - Caso C'VB: sinarome 'one-and-a-half': aspectos clinicos. A, 'one': perda do olhar conjugado horizontal para a esquerda. B, 'half': perda da adução do olho esqueräo, com abducão preservada, durante o olhar conjugado horizontal para a direita. $C$, olhar vertical para cima. $D$, olhar vertical para baixo. E, mirada de repouso, com exotropia à direita, contralateral à lesão. $F$, paralisia facial periférica à esquerda.

\section{COMENTARIOS}

A SOAH caracteriza-se pela presença de paralisia unilateral do olhar conjugado horizontal associada a oftalmoplegia internuclear. Clinicamente, nota-se paralisia do olhar conjugado para um lado ('ONE') e alteraçāo da adução ao olhar para o outro lado ('A HALF'). O único movimento horizontal inalterado é, portanto, a abduçāo do olho contralateral à lesão, o qual apresenta nistagmo durante a abdução. Os movimentos oculares verticais e, menos constantemente, de convergência estao preservados. Em repouso, a exotropia do olho contralateral não é incomum na fáse aguda da lesāo, como exemplifica o nosso caso 4 . Alternativamente, pode não haver desvio ocular ou, ainda, encontrar-se exotropia do olho ipsilateral à lesão. A exotropia paralitica, atribuída ao desvio tônico contralateral dos olhos, surge pelo envolvimento da FRPP 3,4. O relato ocasional de exotropia ipsilateral à lesão 8 pode-se dever a lesão do núcleo ou fascículo do nervo abducente. Não é raro o acometimento do nervo trigêmio, causando perda sensorial na hemiface ipsilateral à lesão ou, como em nosso caso, o surgimento de paralisia facial periférica. Este achado indica uma lesāo que provavelmente acomete o núcleo do abducente, já que este é cercado pelo genu do nervo facial (Fig. 1C). A localização anatômica precisa da SOAH por estudos de necrópsia 

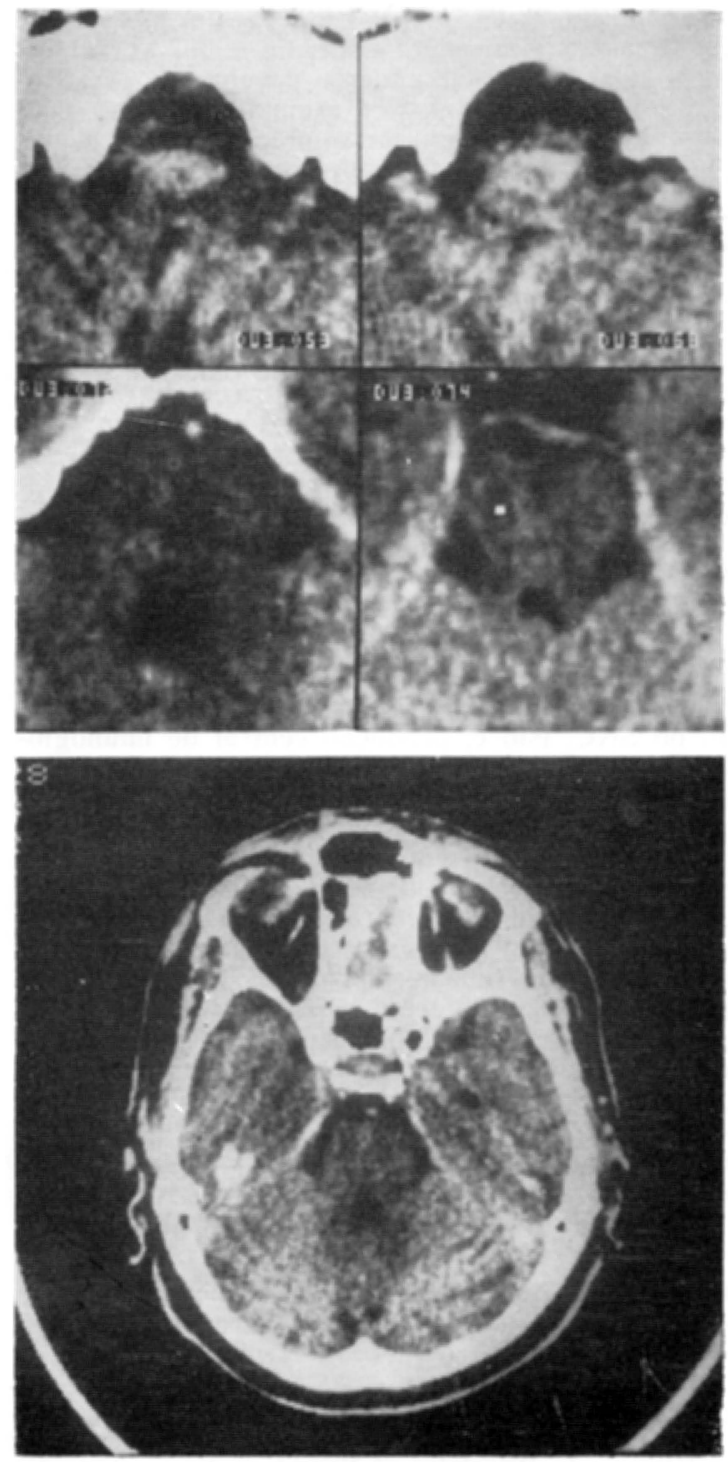

Fig. 3-Craso CVB: aspectos tomográficos. $\mathrm{Em}$ cima, cortes finos $(4 \mathrm{~mm})$ sucessivos ao nivel do tronoo cerebral; abaixo, à direita, nota-se zona hipodensa (*), na ponte, à esquerda; a pequena imayem hiperdensa à frente da ponte, embaixo $e$ à esquerda corresponde à artéria busilar, com contraste em seu interior. Em baixo, ao nivel da ponte, antes da administração de contraste, demonstra-se a zona hipodensa $e$ a atrofia da face anterolateral esquerda du ponte; notar ainda a discutivel atrofia dos hemisferios cerebelares.

só foi feita em poucos casos registrados na literatura, revistos por Wall 8 . Na grande maioria, havia uma lesão do segmento pontino envolvendo tanto o FLM quanto a FRPP. Lesões mais extensas, principalmente de origem vascular, tendem a acometer também o núcleo do nervo abducente e também vias longas (lemnisco medial, feixe piramidal, pedúnculos cerebelares).

No caso clínico aqui relatado, havia um sutil comprometimento do feixe piramidal, manifesto somente pelo sinal de Babinski, sem hemiparesia associada. Este acometimento, porém, nāo se acompanhava de qualquer alteração da sensibilidade, que está geralmente associada nestes casos. A lesão pontina posterior (tegmento pontino), clássica da SOAH, alcança o feixe piramidal na basis pontis por extensão anterior e deveria, portanto, acometer obrigatoriamente o lemnisco medial (Fig. 1C). Duas explicaçōes para esta preservação da sensibilidade corporal não podem ser aqui excluidas. Em primeiro lugar, uma lesāo parcial do lemnisco medial, principalmente em suas porçōes mais medianas, pode não ter repercussão clínica óbvia. É o que acontece, como regra geral, nos casos de infarto pontino medial superior por oclusão 
dos ramos paramedianos da porção superior da artéria basilar 1 . Esta lesão parcial parece provável em nosso caso, já que também o acometimento piramidal era claramente muito restrito. Alternativamente, o quadro clínico poderia dever-se à presença de uma lesão associada porém distinta do feixe piramidal, por exemplo, por patologia desmielinizante (esclerose multipla), como veremos na discussão etiológica que se segue.

Diversas causas raras foram descritas em casos de SOAH 2,5,8, mas podem ser excluidas em nosso caso, seja pelo aspecto tomográfico e evolução clínica (gliomas pontinos e cerebelares, lesões metastáticas, ependimomas do quarto ventrículo, hemorrágia pontina), pela história clinica (trauma) ou pelo detalhado estudo angiográfico (aneurisma da artéria basilar). Mal-formaçăo arteriovenosa foi sugerida inicialmente, mas não pode ser confirmada pelo estudo angiográfico cuidadoso do sistema vértebro- basilar. As discutiveis alterações dos ramos paramedianos distais da artéria basilar, à esquerda, também não foram características de processo vasculítico, em princípio plausivel, já que o paciente fez uso irregular de cocaina por via inalatória; ou de oclusão trombótica destes vasos. A obstrução vascular embólica, entretanto, pode não ser detectada em estudos angiográficos realizados após vários dias de instalaçāo do quadro neurológico. Seria extremamente improvável, porém, a ocorrência de alteraçōs exclusivamente pontinas, ao longo de anos, sem qualquer outra manifestação embólica. Além disso foram excluidas as possiveis patologias vasculares ou cardiacas emboligênicas, pelos exames ecocardiográfico, dopplerométrico e arteriográfico realizados.

Finalmente, a possibilidade de uma doença desmielinizante deve ser estudada em detalhe. O diagnóstico de esclerose múltipla baseia-se, em primeiro lugar, na detecção de acometimento multifocal do sistema nervoso central (SNC) e, de forma imporțante, na constatação de imunoliberação no $\mathrm{SNC}$, isto é, produção central de imunoglobulinas. Como vimos, a primeira condição nāo foi inteiramente satisfeita, já que todas as manifestações clínicas poderiam ser explicadas por uma única lesāo pontina. $O$ exame dos potenciais evocados falhou em demonstrar qualquer outro sitio de acometimento subclínico. A possibilidade de que o acometimento piramidal corresponda a uma lesão independente, porém, não pode, como vimos na discussão acima, ser afastada. A TC parece reforçar esta hipótese, já que demonstrou atrofia focal pontina anterolateral não diretamente relacionada com a lesão hipodensa do tegmento pontino. Além disso, ela levanta a suspeita de leve atrofia cerebelar adicional. É possivel que o exame por ressonância nuclear magnética, reconhecidamente mais sensivel que a TC na detecção das freqüentes zonas periventriculares de hipodensidade por desmielinizáçāo, confirme definitivamente, quando disponivel, o caráter multifocal da doença em nosso paciente. Da mesma forma, não foi possivel obter a confirmação plena pelo LCR de atividade imunológica alterada no SNC, mas havia discreto aumento das proteinas totais e, mais importante, do teor de $\operatorname{lgG}$, como referido em todos os casos de SOAH por doença desmielinizante descritos até aqui 8 . $O$ diagnóstico de esclerose em placas, parece ser o mais plausivel, tendo sido iniciado tratamento imunossupressor especifico para a recorrência mais recente.

Agradecimentos - Gostaríamos de expressar nossa gratidão aos Doutores Hamilton Clemente e Sergio Szklarz pela realização dos exames de LCR e dos potenciais evocados, respectivamente; ao Doutor Rubens Pinheiro pela realização dos exames radiológicos.

\section{REFERENCIAS}

1. Adams RD, Vitor M - Cerebrovascular disease. In Principles of Neurology Ed 3. McGrawHill, New York, 1981.

2. Bogousslavsky J, Meienberg $O$ - Eye-movement disorders in brainstem and cerebelar stroke. Arch Neurol 44:141, 1987.

3. Crevits L, de Reuck J, Vander Eecken $\mathbf{H}$ - Paralytic pontine exotropia in subarachnoid hemorrhage: a clinicopathologic correlation. Clin Neurol Neurosurg 78:269, 1975.

4. Fisher CM - Some neuro-ophthaimological observations. J Neurol Neurosurg Psychiat $30: 383,1967$.

5. Fontanari JL, Vaitses VC, Cruz CN, Tichauer TAT, Lisboa L, Souza ES — Paralisia do olhar conjugado lateral associada a oftalmoplegia internuclear unilateral em hemorragia mesenéfalo-pontina aita. Arq Neuro-Psiquiat (Sāo Paulo). 44:383, 1986.

6. Goebel HH, Komatsuzaki A, Bender MB, Cohen B - Lesions of the pontine tegmentum and conjugate gaze paralysis. Arch Neurol 24:431, 1971.

7. Masdeu JC - The localization of lesions in the oculomotor system. In Localization in Clinical Neurology. Little Brown, Boston, 1985.

8. Wall M, Wray SM - The one-and-a-half syndrome: a unilateral disorder of the pontine tegmentum. A study of 20 cases and review of the literature. Neurology 33:971, 1983.

9. Zee DS, Leigh RJ - Disorders of eye movements - Neurol Clin North Am 1:909, 1983. 